4 Olivarius de Fine F, Worm A-M, Sand Petersen C et al. Sexual behaviour of women attending an inner-city STD clinic before and after a general campaign for safer sex in clinic before and after a general campaign

5 DeBouno BA, Zinner SH, Daamen M, McCormack WM. Sexual behaviour of college women in 1975, 1986 and 1989. $N$ Engl $\mathcal{F}$ Med 1990;322:821-5.

6 Sonnex C, Hart GJ, Williams P, Adler MW. Condom use by heterosexuals attending a department of GUM: attitudes and behaviour in the light of HIV infection Genitourin Med 1989;65:248-51.

7 Opaneye AA, Willmott C. The role of genito-urinary medicine in adolescent sexuality. Genitourin Med 1991; 67:44-6.

\section{Polypoidal and giant molluscum contagiosum in an AIDS patient}

Between $10 \%$ to $20 \%$ of patients with symptomatic HIV disease or AIDS have molluscum contagiosum (MC). ${ }^{1-3}$ Individual lesions of MC may be quite large with a diameter of $10 \mathrm{~mm}$ or more and designated as "giant molluscum contagiosum".4 The appearance of multiple (up to 100) typical papules are more common than solitary papules or plaques of MC. Usually MC lesions are seen over the face (including eyelids), neck and in the intertriginous areas (such as axillae, groins or buttocks) in AIDS patients. ${ }^{5}$ In a recent study from Denmark none of the 16 cases (with MC) out of 122 HIV infected patients had a MC lesion in the anogenital region. ${ }^{4}$

Recently we saw an AIDS patient with multiple (more than 20) asymptomatic MC lesions limited to the penile skin of 3 months duration (fig). The size of the individual lesions varied from 1 to $15 \mathrm{~mm}$ in diameter with no history of spontaneous regression. Two lesions had narrow bases $(8 \mathrm{~mm}$ diameter) and broad tops (12 $\mathrm{mm}$ diameter) like polyps, two were giant molluscum contagiosum and the rest were typical discrete,

Figure Giant molluscum contagiosum of penis. translucent, umbilicated papules. Even on careful cutaneous examination no other part of the body was found to be affected. Curettage and cauterisation with trichloroacetic acid were performed on a few lesions at a time, with the aim of reducing the number and bulk of the lesions.

Giant MC is well known in AIDS patients. The reason for their absence in non-HIV immunosuppressed patients has yet to be explained. Giant MC attaining polypoidal character and limited to the penile skin as seen in our patient is an uncommon presentation.

BHUSHAN KUMAR
GOUTAM DAWN Department of Dermatology, Venereology and Leprology, Postgraduate Institute of Medical Education and Research, Chandigarh-160012, India

Address correspondence to: Dr Bhushan Kumar

Accepted for publication 21 March 1994

1 Sarma DP, Weilbacher TG. Molluscum contagiosum in the acquired immunodeficiency syndrome. $7 \mathrm{Am}$ Acad Dermatol 1985;13:682-3.

2 Matis WL, Triana A, Shapira, et al. Dermatologic findings associated with human immunodeficiency virus infection. $\mathcal{F}$ Am Acad Dermatol 1987;17:746-51

3 Dover JS, Johnson A. Cutaneous manifestation of human immunodeficiency virus. Part I. Arch Dermatol 1991; 127:1383-91.

4 Petersen CS, Gerstoff J. Molluscum contagiosum in HIV infected patients. Dermatology 1992;184:19-21.

5 Johnson A, Dover JS. Cutaneous manifestations of human immunodeficiency virus disease. Fitzpatrick TB, Eisen AZ Wolff $\mathrm{K}$, al, eds Dermatology in General Medicine. AZ, Wolff $\mathrm{K}$, 4th ed, New York McG

Dipyridamole, as an interferon inducer, versus placebo in the prevention of recurrences of condylomata acuminata after diathermocoagulation

Galabov et al have demonstrated that dipyridamole, a drug which has been used for several years for its antiaggregant activity, is an endogenous interferon inducer in guinea pigs ${ }^{1}$ and in man. ${ }^{23} \mathrm{~A}$ single administration of dipyridamole $(100 \mathrm{mg})$ in man induced an increase in the plasma concentration of alpha interferon equal to 195 times the basal values in 36 out of 40 healthy volunteers, detectable up to 48 hours after administration. ${ }^{2}$ A reduction in the plasma concentration of interferon was found, with subsequent administrations of dipyridamole, around 4-6 days after the start of administration of the drug, ${ }^{2}$ similar to what was observed for other interferon inducers. ${ }^{4}$ This period of hyporeactivity has a mean duration of 5-7 days for the interferon inducers studied. ${ }^{4}$

On the basis of these findings, it was decided to verify whether the activity of dipyridamole as an endogenous interferon inducer could modify the course of condylomata acuminata, a disorder which is difficult to treat owing to the frequent recurrences. ${ }^{5}$ Exogenous interferon has been used in the past few years to treat this disorder, with 
results that are not always convincing. ${ }^{5}$ Added to this is the high cost of exogenous interferon and the not-insignificant side effects.

The study included 26 male patients aged between 18 and 62 years, affected by condylomata acuminata of the external genitalia, with onset not more than 30 days previously. The presence of severe organic and haematological changes, of HIV infection and the use, in the 30 days prior to inclusion in the trial, of drugs capable of influencing the response to the treatment excluded patients from the trial.

The patients were assigned at random to one of the following treatments: 13 were treated with diathermocoagulation (DEC) of the lesions followed by administration of dipyridamole, and 13 with DEC and placebo. DEC of the condylomatous lesions was carried out in each patient on inclusion in the study and then repeated in the event of recurrence during the observation period.

Oral administration of dipyridamole and placebo was started on the day after the first treatment with DEC. The dipyridamole dose was $100 \mathrm{mg}$ twice a day on alternate weeks for four consecutive months: this dosage was chosen in consideration of the period of reduction of the serum concentration of endogenous interferon which follows the administration of dipyridamole, ${ }^{2}$ in order to stimulate the most appropriate production of interferon.

The follow-up was carried out every two weeks for 6 months. At each follow-up peniscopy was performed with acetic acid $5 \%$. The effects of the treatment were evaluated on the basis of the number of recurrences, duration of the disorder (patients with no recurrences for at least 3 months were considered as cured, ${ }^{6}$ ) the number of patients cured and any side effects.

There were recurrences of condylomata in 10 patients treated with DEC and placebo and in 5 patients treated with DEC and dipyridamole. Overall there were 27 recurrences in the first group and 11 in the second group. The duration of the disorder (arithmetical mean) was less in the subjects treated with dipyridamole (19 days) compared with the other group (45 days). These differences were shown to be statistically significant on application of the Student's $t$ test, even though the small number of cases constitutes a limitation in drawing statistically certain conclusions.

At the end of the follow-up eight subjects treated with DEC and placebo and 12 subjects treated with DEC and dipyridamole were cured. No side effects were observed during treatment with dipyridamole.

At the end of this clinical observation it can be concluded that the use of dipyridamole in the treatment of condylomata acuminata led to a net reduction in the number of recurrences and of the duration of the disorder compared with the patients who were not treated with this drug. This would appear to confirm the hypothesis ${ }^{7}$ of an antiviral activity of the drug through an induction mechanism of endogenous alpha interferon. These results, achieved with the use of an inexpen- sive and well-tolerated drug, seem encouraging and worthy of confirmation in more extensive series.

$$
\begin{array}{r}
\text { G MANCUSO } \\
\text { M REGGIANI } \\
\text { R M BERDONDINI } \\
\text { A ERRANI } \\
\text { Department of Dermatology, } \\
\text { Municipal Hospital of Lugo (RA), } \\
\text { Italy }
\end{array}
$$

Accepted for publication 22 July 1994

1 Galabov AS, Mastikova M. Interferon-inducing activity of dipyridamole in mice. Acta Virologica Prague 1983;27. 356-8.

2 Galabov AS, Mastikova M. Dipyridamole induces interferon in man. Biomed Pharmacother 1984;38:412-3.

3 Konstantinov K, Galabov A, Mastikova M. Interferon response to dypiridamole in lupus erythematosus response to dypiridamole in lupus

4 Levy HB, Salazar AM. Interferon inducers. In: Baron S Coppenhaver DH, Dianzani F, Fleischmann WR Jr, Hughes TK Jr, Klimpel GR, Niesel DW, Stanton GJ Tyring SK, eds, Interferon: Principles and Medical Application. Galveston: University of Texas Medical Branch, 1992;65.

5 Highet AS, Kurtz J. Human papillomavirus (HPV) and warts. In: Champion RH, Burton JL, Ebling FJG, eds, Textbook of Dermatology 5th ed, Vol. 2. Oxford: Blackwell, 1992;897.

6 Della Corte G, Galasso F, Altamura V, Sbano E. Combinazione interferone $\alpha-2 \mathrm{a}$ per via sistemica e diatermocoagulazione versus semplice diatermocoagulazione nel trattamento dei condilomi
Dermatol Venereol 1992;127:309-13.

7 Kozhukharova MS, Slepushkin AN, Radeva HT, et al. Evaluation of the effectiveness of dipyridamole as a means for prevention of acute respiratory viral diseases. Voprosi Virusologii 1987;3:294.

\section{HIV seropositivity in an STD centre in a cosmopolitan city in northern India}

Sexual promiscuity and unsafe sexual practices increase the risk of acquiring sexually transmitted diseases (STDs), a major high risk factor for transmission of HIV infection all over the world, including India. ${ }^{1}$

The present study was designed to estimate the incidence of different STDs including HIV in STD clinic attenders in the capital of India during a two year period (1990-1992). Appropriate laboratory tests were used for confirmation of diagnosis of STDs. The HIV antibody status was determined by HIV ELISA after pretest counselling. The ELISA positives were confirmed by Western blot test.

The incidence of various STDs is shown in the table. Gonorrhoea, syphilis and chancroid were the commonest STDs in males. Earlier report from northern India ${ }^{2}$ also indicates that these three STDs are the commonest. In females, trichomonas vaginitis was the most frequently diagnosed infection.

One thousand, two hundred, and twenty nine individuals were tested for HIV and six $(0.5 \%)$ were found to be positive. Five were male and one female. The lone female was the marital partner of one of the HIV seropositive patients. All of them were in 21-30 years age group. Three out of six HIV seropositive 